\title{
PROSTITUIÇÃO, PROPRIEDADE E LEGALIDADE: UMA ANÁLISE DO CONTO LEÃO-DE-CHÁCARA, DE JOÃO ANTÔNIO
}

\author{
Diego Kauê Bautz \\ Mestrando pela UNESP \\ diegobautz@hotmail.com
}

\section{RESUMO}

Através da análise do conto Leão-dechácara (2008), de João Antônio, pretendeu-se observar o modo de elaboração de uma voz de contestação aos documentos oficiais de um determinado período histórico da cidade do Rio de Janeiro. Para que este objetivo fosse alcançado, partiu-se de uma análise do texto para propor um diálogo, apoiado em Benjamin (1987), com o seu contexto de produção e as suas reverberações no presente. A leitura, então, indicou que o conto constrói a perspectiva de um sujeito pobre que não hesita em explorar mulheres para garantir uma aparência burguesa, e que reverbera na permanência da noção de legalidade orientada por uma concepção de classe que evita o questionamento daqueles que pertencem ao campo dos proprietários, ao passo que é utilizada como ferramenta de perseguição aos pertencentes às classes eleitas como perigosas.

Palavras-chave: João Antônio; Prostituição; Burguesia; Classes; Propriedade.

ABSTRACT
Through the analysis of the short story Leão-de-chácara, by João Antônio (2008), it was intended to observe the elaborating way of a protest voice against official documents of a certain historical period of the city of Rio de Janeiro. In order to achieve this objective, we started with a careful analysis of the text to build a dialogue, based on Benjamin (1987), with its context of production and its reverberations in present. The reading, then, has indicated that the tale builds a poor guy perspective who does not hesitate to exploit women to guarantee a bourgeois appearance, and that reverberates in the permanence of the legality notion guided by a class conception that avoids the questioning of those who belong to the proprietors field, whereas it is used as persecution tool to those belonging to the elected dangerous classes.

Keywords: João Antônio; Prostitution; Bourgeoisie; Classes; Property.

Lombardo (1991) indica uma proximidade entre o universo da leonagem elaborado em Leão-de-chácara e a ética burguesa em que a competição e a propriedade são enfatizadas. 
Corrêa (2002), além disso, nota uma dissimulação do narrador-protagonista que lhe permite transitar entre a figura do otário, do esperto e do burguês. Por outra perspectiva, Junqueira (2013) observa o modo como o narrador organiza a retrospectiva da sua vida em relação ao espaço e às personagens que lhe cercam como uma forma não egóica de se conscientizar de sua própria condição, o que influenciaria também no estilo de linguagem que reflete a violência que o atinge e o faz reagir no mesmo tom, em direção aos mais abastados. Esta análise propõe pensar sobre um modo diferente de relação com o espaço e o tempo que flexiona os limites da legalidade, pois ao mesmo tempo em que a figura do leão de chácara seja típica deste período, traz consigo também os conflitos e os aspectos mais humanos marcados na elaboração do discurso de Jaime, o narrador-protagonista, que demonstra uma reação a partir de sua angústia diante da chegada da velhice e das mudanças do seu entorno com o passar dos tempos.

O conto, publicado pela primeira vez em 1975, se passa em uma época em que o registro da voz subalterna era praticamente inexistente, sem oferecer quase nenhum espaço para a contestação das versões oficiais, o que permitiu traçar sugestões de como as camadas marginalizadas percebiam este período. Mas, por se tratar de uma elaboração ficcional, pretendeu-se, principalmente, observar o modo como a elaboração da linguagem atua para a construção da identidade deste sujeito, que se coloca a todo o momento em uma relação colada aos espaços que percorre ao passar do tempo. Desejou-se, por fim, observar a forma com que os acontecimentos históricos, como a Segunda Guerra Mundial e o IV Centenário da cidade do Rio de Janeiro são trazidos para dentro do texto. Para isto, inicialmente foi realizada uma análise do conto levando em consideração o modo como narrador, personagens, tempo, espaço e enredo se relacionam. Então, partindo da direção oferecida 
pelo texto de um narrador que se posiciona na ilegalidade e busca se defender dos aparatos legais que dificultam sua subsistência, foi observada, de acordo com Benjamin (1987), a ideia de felicidade que este narrador constrói no que se refere à sua época e aos acontecimentos a que se remete. Ou seja, da mesma forma que Benjamin defende que cada época marque de um modo a felicidade ligada à imagem da salvação, nesta análise também, para refletir sobre o modo como o discurso da ilegalidade poderia ter respondido ao da legalidade no momento do IV Centenário, buscou-se preencher o tempo do passado com "agoras" entendendo, conforme Benjamin, que a imagem do presente inevitavelmente espelhe o seu tempo e que o passado só se deixe fixar no rápido momento em que relampeja.

O progresso para Benjamin (1987), é uma tempestade que, ao mesmo tempo em que acumula ruínas, afasta a história dos fragmentos do passado e a impele para o futuro. Neste sentido, Leão-de-chácara oferece a possibilidade de questionamento ao discurso oficial em torno do IV Centenário associado à ideia de progresso, a partir da ideia benjaminiana de que seja preciso dissociar a política da ideia de progresso, para romper com a subordinação a um aparelho incontrolável e com o conformismo que exalta o trabalho industrial, como conquista política do desenvolvimento técnico sem considerar as falhas na organização da sociedade. Como uma tentativa de forçar um pequeno rompimento, a análise seguiu um movimento dialético entre estudos históricos sobre o período em que se passa o conto, e a observação do modo como a elaboração da linguagem no conto é afetada por este chão histórico, com o intuito de aproximar a concepção progressista ligada a este período.

Desta forma, aqui, o olhar privilegiou a constituição do tempo na narrativa em relação à forma como o narrador-protagonista atua e é afetado por sua época para que, assim, fosse 
possível perceber, a partir do presente, fragmentos do antigo desejo de progresso associado ao IV Centenário da cidade do Rio de Janeiro e a maneira como ilegalidade e legalidade se aproximam entendendo, conforme Benjamin (1987), que seja mais produtivo pensar no modo como uma época anterior entra em contato com a época deste trabalho, do que tecer acontecimentos históricos a partir de suas causas.

O que o narrador de Leão-de-chácara chama de "limpeza" promovida pela polícia na ocasião do IV Centenário da cidade do Rio de Janeiro, em relação aos personagens ligados a atividades de rua, exerce uma importante função no conto. Não pensando sobre o IV Centenário da cidade do Rio de Janeiro, mas sobre as comemorações em torno do IV Centenário do descobrimento do Brasil, Oliveira (2000) aponta estes eventos como uma forma de o Brasil celebrar as suas possibilidades associadas às ideias de progresso que colocavam algumas classes como indesejadas. "A reforma urbana desenvolvida pelo prefeito Pereira Passos pretendeu modernizar, limpar, iluminar as ruas do Rio de Janeiro e sanear a vida urbana afastando os indesejáveis, as 'classes perigosas' do centro da cidade" (OLIVEIRA, 2000, p. 190).

As melhorias materiais nas cidades na virada do século XIX para o XX, de acordo com Junior (2010), simbolizavam a reprodução do comportamento europeu associado à ideia de progresso e modernidade, que contrastava com a exposição da miséria nas áreas centrais das cidades em que pessoas pobres se agrupavam. Esse contraste, de acordo com o pesquisador, fez com que o imaginário em torno da pobreza fosse associado à ameaça à família e à propriedade e que, por isso, devesse ser combatida através do controle social escamoteado pela repressão policial. 
Pensando em um contexto mais recente, Leite (2014) indica que as favelas passaram a ser o território específico associado à ideia da criminalidade que deve ser combatida pelo controle policial. Esse controle, no entanto, conforme a pesquisadora, gera uma metáfora de guerra em que a violência por parte do Estado acaba justificada nesses espaços pela suposta necessidade de reprimir aqueles que se desviem do conceito de legalidade, como, por exemplo, os traficantes, e de disciplinar os moradores presumivelmente próximos aos criminosos.

Desta forma, a força com que a polícia atua em determinados territórios considerados ameaçadores se apoia na defesa da legalidade, embora, como demonstrado por Leite (2014), os alvos desse policiamento sejam determinados muito mais por pertencerem a classes consideradas perigosas, como os moradores de favelas sem envolvimento com o crime, do que pela defesa da legalidade. Miranda (2014), ao analisar o discurso político no Brasil em torno dos conceitos de legalidade e ilegalidade no período entre 1945 e 1964, identifica que, após a consolidação do Golpe de 1964, o discurso em defesa da legalidade constitucional democrática se orientava de maneira maleável, dependendo dos interesses políticos daqueles que o mobilizavam. Como, por exemplo, o veículo Tribuna da Imprensa que, aliado da ditadura, propunha uma nova legalidade que justificasse os abusos cometidos na chamada "revolução 'brasileira', 'autêntica' e 'verdadeira', [que] diferenciava-se da outra, 'comunista', aproximando-se da ideia de ordem, de paz e de conformidade com os valores cristãos" (MIRANDA, 2014, p. 572-573).

Como se vê, o conceito de legalidade, tão caro a esse período, esteve mais associado ao moralismo do que ao efetivo cumprimento da lei. Leão-de-chácara trata sobre práticas 
que podem ser entendidas, sob essa perspectiva conservadora, tanto imorais quanto ilegais. No entanto, em relação à prostituição e tudo o que a envolve, como a figura dos leões de chácara, a constituição da ideia de legalidade no Brasil também fora problemática. Silva e Santos (2015) apontam que, no final do século XIX, embora a prostituição fosse vista como um problema a ser controlado, somente as prostitutas eram alvos da repressão que fazia vistas grossas aos que patrocinavam essa prática. De acordo com Silva e Santos, somente em 1879, após reclamações de comerciantes das áreas centrais do Rio de Janeiro sobre a alta dos preços de aluguéis motivada pelas atividades dos então chamados proxenetas é que houve perseguição a essas figuras. Porém, resolvida essa questão em termos comerciais, a prostituição voltava a ser vista com complacência, favorecendo os cafetões e prejudicando não só as prostitutas, mas grande parte das mulheres que viviam no Rio de Janeiro. Isso porque, ainda em 1879, conforme Silva e Santos, o comandante da Primeira Estação de Guardas Urbanos, o tenente Heller, se propõe a acabar com o que chama de "escândalos das niniches" prendendo todas as mulheres encontradas nas ruas após as 22 horas em um "xadrez para mulheres", sendo elogiado pela imprensa por ter livrado as ruas dos chamados vagabundos. No entanto, esse "xadrez para mulheres" fora descoberto como um instrumento policial para extorquir as prostitutas que se viam exploradas tanto pelos cafetões quanto pelos policiais.

Nesse sentido, o conto Leão-de-chácara apresenta, logo de início, alguns elementos que sugerem os disfarces em relação às funções dos espaços no controle das mulheres, pois começa ao acender das luzes de um letreiro de boate na Zona Sul, onde o narrador se apresenta. Essa boate é descrita pelo narrador como um lugar que conta com uma "porta de madeira falsamente antiga, trabalhada e de dourado" (2008, p. 29) e frequentado por 
pessoas a quem as trata com a mesma falsidade que o espaço sugere. Após a apresentação do espaço de enunciação, o narrador passa a fazer uma retrospectiva de sua vida, partindo dos variados trabalhos que desempenhou nas ruas. Sua retrospectiva passa pela Lapa Antiga, localizada, na realidade, na região central da cidade do Rio de Janeiro, caracterizada pelo narrador como um bairro que contava com cabarés que recebiam pessoas consideradas importantes. O leitor, então, conhece Pirraça, "nome de guerra" que o narrador ganhou nas ruas após ter aprendido "debaixo de porrada, a ver sem salamaleques as coisas desta vida". Além disso, as ocupações de Pirraça são informadas - "Engraxei, lavei carro, vendi flores, amendoim, fui moleque de vida brava [...]" -, um pouco mais adiante - "Não me dei bem como garção. Meu negócio forte era a briga, aprendida sempre em becos e ladeiras" (2008, p. 30) -, e, ainda - "Muita vez o jogo me ajudou a levantar algum trocado. Tive mulher na vida, na rua ou nos dancings, se virando e mordendo os trouxas" (2008, p. 31). Desta forma, a alcunha de Pirraça ganha sentido por evidenciar que ele fora "desde pixote [...] um mordido, um embirrado" (2008, p. 30), pois a imagem construída é de uma personagem boa de briga no sentido de adotar uma atitude cada vez mais disposta a contrariar o estabelecido como, por exemplo, as virações ilegais que realizava contraposta à sua indisposição ao trabalho de servir como garçom.

Após sumariar suas fases de moleque de rua, garçom sem sucesso, brigador e leão, a voz narrativa volta ao presente. Neste ponto, além de reflexões sobre como a vida exige um estado de alerta, o narrador contrapõe seu estado atual em que pega trem todos os dias para trabalhar ao tempo em que enaltece como um "tempo de ouro" que tivera um carro. Esse tempo de ouro é evocado e datado pelo narrador no pós-guerra, entre 1945 e 1955 "Até o finalzinho da guerra, em 45, e depois até as beiradas do ano de 55 " (2008, p. 33). No 
conto, esse tempo é caracterizado como a época das cafetinas em que as casas noturnas eram frequentadas por estrangeiras e endinheirados, e tinham a segurança garantida por uma Polícia Especial. Neste momento, Pirraça ameniza o seu posicionamento de enfrentamento ao se colocar, de forma humilde, ao lado dos mais fracos - "No mundo tem dois tipos de gente: os que aturam e os que faturam. E a grana vai falando mais alto e grosso. Cá de minha parte, tenho faturado pouco e aturado muito" (2008, p. 31). As perdas então, marcadas já em faturado/aturado, passam a aparecer na estória, sempre de forma escamoteada pelo narrador, que Ihes atribui o aspecto positivo de the servirem como disfarce.

Da mesma forma, o narrador defende que prefere ser visto como "um porteirinho mixuruco e só" do que como "leão-de-chácara", pois, em suas palavras: "Prefiro que os trouxas me tratem como porteiro, como seu Zé ou como Pirraça. Já é um disfarce, um agá" (2008, p. 32). Disfarce que, aliás, faz com que em trinta anos de trabalho poucos conheçam o seu nome - Jaime. Por outro lado, ao revelar o seu verdadeiro nome ao leitor, o narrador parece mostrar o lado oposto de Pirraça, ou seja, um lado que confessa: "eu gosto de respeito e distância com os fariseus a quem sirvo e aturo. A mim, quando me convém, respeito até vendedor de amendoim" (2008, p. 33). Neste ponto, Jaime se revela disposto a servir ao mesmo tempo em que se demonstra ameaçado pelas novas figuras de Leão-dechácara.

Saindo um pouco de si, o narrador passa a traçar uma história da vida noturna do Rio de Janeiro. De acordo com a sua perspectiva, as casas de noite, ou, segundo ele, "cabarés e bordéis de polacas francesas" eram frequentados por "otários endinheirados, figurões que 
não podiam ser vistos na farra" (2008, p. 33) que gastavam grandes quantias de dinheiro nesses lugares. Essa descrição serve para o narrador passar a diferenciar a sua atividade nesse tempo, da do tempo da narração. Segundo Jaime, no período entre 1945 e 1955 quem fazia a segurança das noites era gente de confiança dos "majorengos da lei" que se caracterizava pelas habilidades em lutas aprendidas nas ruas, e, dentre essa "gente", destaca o trio "Guarabira, Cachacinha e Caruara. Valentes muito sérios, professores de briga, ferviam, encaravam, arrepiavam os ambientes mais pesados e até os bailes do carnaval antigo. Espertos como relógios" (2008, p. 34). O tempo passado é caracterizado pelo narrador como um momento em que os leões conseguiam lidar com o público heterogêneo que frequentava as casas, sendo coniventes com os mais poderosos e autoritários com os menos poderosos. Tal comportamento é contraposto ao dos leões recentes que, de acordo com o narrador, embora tenham poder nas margens da Praça Mauá porque "As ondas mudaram a cidade, as marés da boêmia já tocaram do centro para a Zona Sul, já voltaram para o Centro e hoje estão divididas" (2008, p. 36), não têm o mesmo tato que os antigos e acabam provocando tumultos ao mexerem com personagens influentes. Aqui, então, o espaço é caracterizado em constantes mutações em que a vida noturna trafega por diferentes regiões da cidade, conforme "as ondas" determinam.

Jaime, então, se coloca em posição crítica aos leões do tempo do seu enunciado, e ilustra a sua opinião contando a história de um "leão" mais novo, conhecido por Miguelito que, apaixonado por uma dançarina chamada Maricele, atira em um freguês que sairia com ela. O narrador aproveita o seu relato para defender que os "leões" de seu tempo não vacilavam como os do tempo do seu enunciado, pois seguiam o modelo de conduta sugerido por ele: "uma lei dos malandros: a gente vê com os olhos e lambe com a testa. E fica 
esperando a hora. Depois, então, come com a boca toda. É de lei. Outra coisa: quem tem ciúme de marafona é coronel" (2008, p. 37).

O caso de Miguelito serve também para o narrador ilustrar o momento em que os bordéis perdem espaço para as boates, como a que Jaime trabalha no momento da narrativa. Esta mudança, para o narrador, tem seu ápice no IV Centenário da cidade em que houvera uma tentativa de eliminar as figuras da rua, em razão da passagem pela cidade de pessoas consideradas importantes.

Foi um arrastão - ladrão, marafona, pedinte, maltrapilho, indigente, esmoleiro, cego de rua, engraxate, aleijado, limpador de carro - e toda a arraia-miúda andou mal de vida, indo mofar no xadrez. A vida cachorra é assim. Os homens lá em cima assinam um papel e a gente aqui embaixo, na vida que vai comendo quente, aguentando ripada no lombo e cadeia. Comendo o pão que o capeta amassou com o rabo. (ANTÔNIO, 2008, p. 38)

A fala do narrador, que se coloca não ao lado, mas entre a "arraia-miúda" inicialmente pode sugerir uma voz que se coloca a serviço do grupo para expor o sentimento destes personagens sujeitos às vontades dos "homens lá em cima". Ilustra também algumas das motivações e consequências das mudanças na vida noturna da cidade naquele período, pois o regime de confiança apresentado antes da leonagem é substituído pela instabilidade de leões suscetíveis a "vacilos" como o de Miguelito, e as boates que, de acordo com Jaime, eram frequentadas por soldados que se aliviavam dos sofrimentos da guerra, vieram a ser frequentadas pelo que chama de "trouxas". Entretanto o narrador revela que em vez de se colocar a serviço do grupo, buscou tirar proveito da situação em defesa da sua sobrevivência - "Quem ganhou com a limpeza fui eu. E os outros, os leões, a leonagem raiada. A gente começou a nadar de braçada, à vontade e com folgança" (2008, p. 39). 
As chamadas ondas, conforme o narrador, fizeram com que "a vida das mulheres na rua" (2008, p. 38) passasse por tempos difíceis, pois como se tornaram alvo constante de investidas policiais, tiveram de se "enrustir" nos chamados inferninhos. Tais investidas seriam motivadas pela "limpeza" promovida na cidade pelos "homens dos costumes". Como consequência, o narrador lamenta a desvalorização dos Cabarés que, no tempo de sua fala, vão desaparecendo. Nota-se, então, que o espaço, assim como o discurso de Jaime, vai se maquiando. A prostituição exibida nas ruas se esconde nos inferninhos após a "limpeza". O tempo do enunciado do narrador, no mesmo sentido, contraposto ao tempo de ouro, é marcado pelos vacilos da leonagem e por uma tranquilidade aparentemente dissimulada de Jaime. De acordo com as suas palavras: “Não, não que eu tenha saudade do passado, que hoje vivo bem mais na sombra do boi do que os antigos" (2008, p. 36).

O discurso de Jaime é tão movediço quanto o relato de sua vida sugere. Ao se apresentar, o discurso do narrador aparece contrário à leonagem. "Deram para xingar esta minha viração de leão-de-chácara. Não gosto do nome. Ele marca e deixa na cara uma situação de fortaleza e mando. Isso é ruim" (2008, p. 32). Depois da limpeza da cidade o discurso se metamorfoseia. Jaime se une aos leões para não ser levado junto com a "arraiamiúda" - "Deitando e rolando, nossa patota foi se fazendo dona da noite. Tomamos o campo, nos unimos em conluio e dividimos a cidade" (2008, p. 39). E, por fim, afirmando que "os valentes passaram a ser os leões", o narrador apresenta pela primeira vez uma ideia favorável ao tempo presente da sua fala em comparação com o passado ao defender que os leões sejam melhores para as mulheres do que os cafetões de tempos anteriores, já que os leões não seriam tão rígidos porque não viviam exclusivamente da renda delas como faziam os cafetões. Embora sua afirmação seguinte coloque em xeque essa opinião - "Escreveu, 
não leu, já viu: a gente machuca mesmo. Bate como se estivesse malhando um homem. Sem os leões, elas não vivem. Meu apelido é Pirraça e ele não me chegou sem bom motivo" (2008, p. 40).

O modo como Jaime se expressa em relação às mulheres, não só as enxergando como produtos, mas também as ofendendo, marca o modo como o próprio personagem do narrador é construído como um personagem que se coloca contra tudo e só se junta a algum grupo visando algum benefício próprio - para gerar empatia quando se coloca ao lado da "arraia-miúda", e para sobreviver fazendo valer a sua palavra junto aos "leões".

Sendo assim, para o narrador, aparentemente a passagem do tempo é vista como positiva em razão da crescente influência dos leões, pois os negócios giravam em torno das mulheres que trabalhavam nas boates em que eles exerciam o controle através de extorsões. No entanto, essa passagem do tempo é o que mais o angustia não só por sentir a idade chegar, mas principalmente por entender que seu posto de trabalho passa a ser ameaçado por jovens desempregados. Talvez por isso o narrador argumente que os leões mais novos não possuam a mesma esperteza que os leões mais velhos. Além disso, é possível perceber também uma diferenciação social entre as duas gerações. Jaime, assim como os leões mais velhos, são descritos como personagens pobres que tudo aprendiam nas ruas e que brigavam, em todos os sentidos, para sobreviver, enquanto que os leões mais novos, de acordo com o narrador, "É tudo rapaz desempregado, do tipo boa-vida e bonitão, alguns até de família. Trambicam como leões porque não têm capacidade ou não encontram outro jeitão de vida. De comum, passaram por academia de luta e vivem pretos de sol e praia" (2008, p. 42). Jaime, então, parece, por um momento, se livrar completamente do seu 
disfarce revelando o que a vida lhe fez, pois revela a sua idade, o lugar e o modo em que mora, além de informações sobre seus gostos, sua rotina e sua família, o que constitui uma imagem totalmente oposta a dos leões mais novos.

Que não sou menino, já disse. Moro na Zona Norte, lá onde o Judas perdeu as botas, viajar nos trens da Central não é refresco. Estou nos 48, tenho dois bacuris no colégio, uma mulher honesta. Na minha casa, em Inhaúma, tem uma horta e um papagaio que veio do Pará. Depois do almoço, me distraio cachimbando, dando um tapa na terra e apanhando sol. Gosto disso tudo e bem. Também acontece que os meus cabelos estão pintando de branco. E não posso brincar em serviço. (ANTÔNIO, 2008, p. 43).

Portanto, aquele que um dia fora Pirraça, das brigas de rua e da leonagem, mostra-se agora como um personagem angustiado diante da velhice e que se defende como pode dos jovens que ameaçam a sua continuidade como leão. O modo como o narrador vai mudando de opinião em relação aos leões, mas sempre tendendo a enaltecer os mais antigos em detrimento dos mais novos sugere já uma defesa da sua própria condição, evidenciada ainda mais quando revela a sua preocupação com a chegada dos cabelos brancos e dos jovens de academias, pois neste ponto Jaime vai contrapondo negativamente os seus sinais de idade, como os cabelos brancos e "um pouco de barriga" (2008, p. 43), aos aspectos positivos da juventude dos novos leões, como a força, o conhecimento de lutas adquirido em academias e a prática de esportes, para, enfim, mostrar-se, também através de disfarces, de modo "enrustido, mas fazendo volume do lado de fora...", pronto a defender o seu posto:

Onde há tutu, os piranhudos vêm morder. E já era assim no tempo dos antigos. Por essas e por outras, isto aqui que trago à direita da cintura, enrustido, mas fazendo volume do lado de fora do paletó, não é nenhuma lata de vaselina. É uma automática, de pente pronto, cheio, dessas máquinas de guerra que comprei de 
um marítimo e que só os majorengos das três armas podem usar. (ANTÔNIO, 2008, p. 44).

\section{CONSIDERAÇÕES FINAIS}

Sendo então a propriedade, escamoteada pela ideia de progresso, a norteadora da noção de felicidade em Leão-de-Chácara, os limites de conceitos como a legalidade e a ilegalidade se baseiam na distância entre a ordem dos proprietários, que remete à ideologia burguesa, e as estratégias daqueles mais distantes da propriedade. Portanto, a eleição de classes perigosas, no conto, revela que se trata da eleição de classes potencialmente capazes de alterar a ordem que se pretende conservar. Pode-se notar essa ideia no texto observando a maneira como o "tempo de ouro" é construído pelo narrador em torno da defesa realizada por uma Polícia Especial dos endinheirados que frequentavam os bordéis, que, aliás, foram substituídos pelas boates. O que significa que assim como o tempo, também o espaço orientado pelas chamadas "ondas" determinavam os diferentes modos de violências praticadas contra as "classes perigosas", sobretudo contra as mulheres.

O narrador, que já de início, se apresenta ao lado de um falso progresso marcado pelas luzes da boate que se contrapõem à tentativa de se fazer com que a porta parecesse antiga, como em uma espécie de jogo entre uma tradição tão manchada quanto o progresso em curso, marca a maneira como o conto trabalha com a percepção de um sujeito pertencente à classe considerada perigosa que não mede as consequências de seus atos para se adequar ao espaço. As virações exercidas por Jaime revelam um personagem sem escrúpulos que, apesar de aturar mais do que faturar, adota como defesa uma atitude individualista que ilustra um enfraquecimento da solidariedade de classe marcada por sua subserviência aos endinheirados e, no máximo, conveniência aos mais próximos. 
Desta forma, os acontecimentos históricos trazidos ao enredo, mais especificamente o pós-guerra (1945-1955), caracterizado pelo narrador como o tempo de ouro em que os bordéis eram frequentados por poderosos, dialogam com a "limpeza" motivada pela ideia de progresso que trazia o IV Centenário da cidade do Rio de Janeiro, pois se lidou com a concentração de personagens nas ruas, sem se atentar ao problema da pobreza, assim como os bordéis foram substituídos pelas boates sem que a prostituição fosse combatida e, por fim, a violência, em vez de ser enfrentada, acaba potencializada através da substituição das lutas de rua pela arma de fogo. Em suma, a limpeza motivada pela ideia de um progresso que garantisse a posse de propriedades como salvação é, pelo lado dos "homens de cima", favorável em razão das ondas que nunca os afetam, e, do lado do narrador, por mais que afirme ter levado vantagem, revela uma angústia diante da possibilidade de perda da sua aparência burguesa.

A análise de Leão-de-chácara, portanto, vista a partir do presente, permite enxergar a continuidade de uma ideologia modulada pela ideia de progresso associado aos interesses da burguesia, pois se no conto de João Antônio os cafetões sempre encontram um modo de lucrarem com a exploração das mulheres e de se safarem em razão do interesse econômico por trás dessa prática, de acordo com publicação da Carta Capital (2018), na noite de sextafeira, mesmo dia da semana em que se passa a ação do conto, mas no dia seis de Abril de 2018, o conhecido empresário da prostituição Oscar Maroni aparece no palco de sua boate vestido de presidiário e expondo uma mulher nua, à frente das fotos do juiz Sérgio Moro e da ministra do Supremo Tribunal Federal, Carmém Lúcia, com o intuito de comemorar a prisão do ex-presidente Lula, indicando, assim, a continuidade da objetificação do corpo feminino e de uma ideia, amparada pelo não questionamento legal e moral daqueles que 
pertencem ao campo dos proprietários, que busca "limpar" o país de classes consideradas perigosas para que o progresso seja assegurado.

\section{REFERÊNCIAS}

ANTÔNIO, J. Leão-de-chácara. 2. ed. São Paulo: Cosac Naify, 2008.

BENJAMIN, W. Obras Escolhidas: Magia e Técnica, Arte e Política. 3. São Paulo: Editora Brasiliense S.A, 1987.

CAPITAL, C. Profissionais do sexo repudiam Oscar Maroni. Disponível em: $<$ https://www.cartacapital.com.br/sociedade/profissionais-do-sexo-repudiam-oscar-maronie-manifestam-apoio-a-lula>. Acesso em: 17 abr. 2018.

CORRÊA, L. C. Merdunchos, malandros e bandidos: estudo das personagens de João Antônio. Dissertação (Mestrado em Letras) - Programa de Pós-Graduação da Faculdade de Ciências e Letras de Assis (UNESP), 2002.2 Disponível em: <https://repositorio.unesp.br/handle/11449/99162>. Acesso em: 17 abr. 2018.

JUNIOR, C. M. Imagens urbanas assombrosas: controle social nas cidades brasileiras da Belle Epoque. In: Albuquerque: revista de História, v. 2, n. 4. Disponível em: <http://www.seer.ufms.br/index.php/AlbRHis/article/viewFile/3952/3153>. Acesso em: 17 abr. 2018 (2010). p. 83-98.

JUNQUEIRA, D. M. C. Na ponta do taco: as personagens equilibristas de João Antônio. Dissertação (Mestrado em Literatura Brasileira) - Programa de Pós-Graduação em Literaturas Vernáculas da Universidade Federal do Rio de Janeiro (UFRJ), Rio de Janeiro, 2013. Disponível em: <http://www.letras.ufrj.br/posverna/mestrado/Junqueira DMC.pdf>. Acesso em: 17 abr. 2018.

LEITE, M. P. Entre a "guerra" e a "paz": Unidades de Polícia Pacificadora e gestão dos territórios de favela no Rio de Janeiro. In: Dilemas - Revista de Estudos de Conflito e Controle Social, $\quad v$. $7, \quad$ n. 4.4 Disponível <https://revistas.ufrj.br/index.php/dilemas/article/view/7270>. Acesso em: 17 abr. 2018 (2014). p. 625-642.

LOMBARDO, E. L. A desmistificação do malandro em contos de João Antônio. Itinerários. Disponível em: <https://repositorio.unesp.br/bitstream/handle/11449/107004/ISSN0103815X-1991-2-213-223.pdf?sequence=1>. Acesso em: 17 abr. 2018 (1991). p. 213-223.

MIRANDA, M. A. B. DE O. Povo, democracia e legalidade nas linguagens políticas do Brasil (1945 - 1964) e do Chile (1938 - 1973) no contexto das experiências democráticas de massa. Tese (Doutorado em História) - Programa de Pós-Graduação em História Social da Cultura, do Departamento de História da PUC-Rio e à Pontificia Universidad Católica de Chile (PUC), 
Rio de Janeiro, 2014. Disponível em: <www2.dbd.pucrio.br/pergamum/tesesabertas/1011843_2014_pretextual.pdf>. Acesso em: 17 abr. 2018.

OLIVEIRA, L. L. Imaginário Histórico e Poder Cultural: as Comemorações do Descobrimento. In: Revista Estudos Históricos, v. 14, n. 26. Disponível em: <http://bibliotecadigital.fgv.br/ojs/index.php/reh/article/view/2122>. Acesso em: 17 abr. 2018 (2000). p. 183-202.

SILVA, M. DOS S.; SANTOS, M. DOS. O tráfico e a exploração de mulheres na prostituição no Rio de Janeiro na segunda metade do século XIX. In: Ler História, n. 68. Disponível em: <http://journals.openedition.org/lerhistoria/1717>. Acesso em: 17 abr. 2018 (2015). p. 87108.

Artigo recebido em: 19 de abril de 2018. Artigo aprovado em: 20 de agosto de 2018. 